\section{Corneal endothelial function after phacoemulsification using the fluid- based system compared to conventional ultrasound technique}

A Tsorbatzoglou', K Kertész', L Módis', G Németh', J Máth² and A Berta'
Abstract

Aim To quantitatively assess corneal endothelial changes after phacoemulsification with the fluid-based system compared to conventional ultrasound technique.

Methods This prospective, randomized clinical study included patients with cataract who were randomly assigned either to have phacoemulsification with the fluid-based system (30 eyes of 30 patients-Group 1) or with traditional ultrasound (30 eyes of 30 patients - Group 2). Patients who were available at each follow-up visit ( 25 eyes in both groups) were enrolled in the statistical analysis. Endothelial function was evaluated by measuring central corneal thickness, central endothelial cell density (ECD), mean cell size, and coefficient of variation in cell size preoperatively, 10 days, 1 and 3 months, and 1 year after surgery. Statistical analyses were performed using two-way repeated measure ANOVA.

Results An acute, reversible increase of central corneal thickness (CCT) was found $\mathbf{1 0}$ days after surgery, which was similar in both groups $(P=0.35)$. ECD decreased, whereas mean cell size increased significantly immediately after surgery. However, the impairments were finished after 1 month. The alterations were similar in both groups (ECD: $P=0.99$; mean cell size: $P=0.85$ ). The coefficient of variation in cell size remained stable after surgery $(P=0.08)$, and significant difference was not found between groups $(P=0.99)$. The endothelial cell loss $(E C L)$ was
$6.5 \pm 8.4 \%$ in Group 1 and $6.5 \pm 11.7 \%$ in Group

$2(P=0.69)$.

Conclusions Corneal endothelial changes were similar using the fluid-based system compared to the traditional ultrasound technique. The fluid-based method proved to be as safe as conventional ultrasound in cataract surgery.

Eye (2007) 21, 727-732; doi:10.1038/sj.eye.6702314; published online 3 March 2006

Keywords: phacoemulsification; fluid-based system; Aqualase; endothelial cell loss; central corneal thickness

\section{Introduction}

Corneal endothelial cells are especially sensitive to surgical damage. Therefore, endothelial changes and alterations of central corneal thickness (CCT) are considered important parameters of surgical trauma and are indispensable in evaluating the safety of new surgical methods. ${ }^{1-3}$

Endothelial cell loss (ECL) is a complication that has been described in all types of cataract surgery and is widely investigated in the literature. The results on mean ECL vary from 0.4 to $27.7 \%$ after phacoemulsification, depending on different surgical techniques. ${ }^{2,4-20}$

In recent years, new surgical procedures have been developed to reduce ECL, such as laserand fluid-based methods. During the latter procedure, short pulses $(4 \mu \mathrm{l})$ of warmed
${ }^{1}$ Department of Ophthalmology, Medical and Health Science Center, University of Debrecen, Debrecen, Hungary

${ }^{2}$ Department of Psychology, University of Debrecen, Debrecen, Hungary

Correspondence: A Tsorbatzoglou, Department of Ophthalmology, University of Debrecen, Hungary Nagyerdei krt. 98, H-4012 Debrecen, Hungary Tel: + 365241 5816; Fax: + 3652415816 . E-mail: alex@ jaguar.unideb.hu

Received: 8 December 2005 Accepted in revised form: 29 January 2006 Published online: 3 March 2006

Authors have no commercial or proprietary interests in any of the products used in this study 
balanced salt solution liquefy the lens material, while the irrigation fluid surrounds the warmed pulsating fluid allowing cooling of the pulse. ${ }^{21,22}$ There is no ultrasound and heating effect during the procedure. However, its effect on the corneal endothelium is unknown.

The purpose of this study was to quantitatively assess corneal status such as pachymetry, endothelial cell count, mean cell size, and coefficient of variation in cell size after phacoemulsification with the fluid-based system compared to conventional ultrasound technique.

\section{Materials and methods}

\section{Patient selection}

This single-centre, prospective, comparative, randomized clinical study comprised patients with cataract who were randomly assigned, using the standard envelope method just before the surgery, to have phacoemulsification with traditional ultrasound or with the fluid-based system. Thirty eyes of 30 patients were operated on with the water-jet method (Group 1) and 30 eyes of 30 patients with the ultrasound technique (Group 2). One patient from Group 1 withdrew his informed consent after the surgery and one patient died. Eight subjects missed at least one visit (three from Group 1 and five from Group 2). Therefore, only patients who were available at each follow-up visit (25 eyes in both groups) were enrolled in the statistical analysis.

A complete ophthalmological examination was performed on each patient preoperatively. Nuclear hardness was graded by the surgeon using the LOCS III system. ${ }^{23,24}$ Exclusion criteria were any other eye pathology than cataract, age less than 50 years, high refractive errors $(>4 \mathrm{D})$, low endothelial cell count $\left(<1500\right.$ cells $\left./ \mathrm{mm}^{2}\right)$, pupillary dilation problem, and history of any ocular surgery or trauma. After the nature of the procedures had been fully explained, informed consent was obtained from the patients. The research was conducted in accordance with the Declaration of Helsinki and the ethical standards of the local ethics committee.

\section{Surgical technique}

All operations were performed by the same surgeon, who was experienced in both traditional ultrasound and fluid-based techniques.

All surgeries were performed under topical anaesthesia. Clear corneal incision $(3.2 \mathrm{~mm})$ was made at the steepest meridian of the cornea in all cases. The anterior chamber was filled with ophthalmic viscosurgical device (OVD) and one paracentesis was made in the area of $70^{\circ}-90^{\circ}$ left side to the clear corneal incision. After capsulorhexis, hydrodissection and hydrodelineation were performed. The equipment used for the phacoemulsification was the same in both groups (Infiniti $^{\mathrm{TM}}$ Vision System, Alcon Laboratories, Forth Worth, TX, USA). In Group 1, water-jet technique (Aqualase $^{\mathrm{TM}}$ ) was used for fragmentation and emulsification of the nucleus. The fragmentation method was the bimanual divide and conquer technique in the capsular bag, with the original Aqualase ${ }^{\mathrm{TM}}$ tip. In Group 2 , traditional ultrasound was used to remove the nucleus using the same bimanual divide and conquer technique (with $0^{\circ}$ flared tip). In all cases, the same irrigating solution (BSS Plus ${ }^{\mathrm{TM}}$, Alcon Laboratories) and OVD (Amvisc Plus ${ }^{\mathrm{TM}}$, Bausch and Lomb Incorporated, Rochester, NY, USA) were used. Flow conditions and vacuum settings were standardized for all eyes. The removal of the nucleus was followed by irrigation/ aspiration of the cortex and capsular polishing in both groups. After filling the capsular bag with OVD, singlepiece hydrophobic acrylic intraocular posterior chamber lens (Acrysof ${ }^{\mathrm{TM}} \mathrm{SA} 60 \mathrm{AT}$, Alcon Laboratories) was implanted in the bag using injector. The OVD was aspirated and the anterior chamber reformed with BSS Plus ${ }^{\mathrm{TM}}$. The clear corneal incision was left sutureless. The corneal wound and the side port were hydrated with BSS Plus ${ }^{\mathrm{TM}}$, and dexamethasone (DexaRatiopharm $^{\mathrm{TM}}$, Merckle GmbH, Ulm, Germany) and tobramycine (Brulamycin ${ }^{\mathrm{TM}}$, Biogal, Debrecen, Hungary) were administrated by a subconjunctival injection. The eyes were patched with gentamycine + bethamethasone ointment (Garasone ${ }^{\mathrm{TM}}$, Schering-Plough Europe, Brussels, Belgium). All procedures were uneventful.

At the end of the surgery, the following variables were recorded: fluid-based time, number of pulses, average fluid-based magnitude, effective fluid-based time, aspiration time, and surgery time in Group 1, and phaco time, average ultrasound power, effective phaco time, aspiration time, and surgery time in Group 2. Effective phaco and fluid-based time is the time that theoretically would be necessary for the same surgery had $100 \%$ ultrasound or fluid-based power been used throughout (effective phaco time $=$ phaco time $\times$ mean phaco power $/$ 100 , effective fluid-based time $=$ fluid-based time $\times$ mean fluid-based magnitude/100).

Postoperatively patients received tobramycine + dexamethasone eyedrops (TobraDex ${ }^{\mathrm{TM}}$, Alcon Laboratories) five times for 4 weeks. The patients were examined on the first postoperative day, when the best-corrected distance visual acuity (BCDVA) (using ETDRS chart with constant illumination), intraocular pressure, and slit-lamp findings were recorded. Complete ophthalmological examination was performed (including BCDVA, anterior segment biomicroscopy, 
binocular fundus examination, ultrasound pachymetry, specular endothelial microscopy, corneal astigmatism, and intraocular pressure measurement) 10 days, 1 and 3 months, and 1 year after the surgery.

\section{Endothelial cell analysis}

Specular endothelial microscopy was performed in local anaesthesia with the wide field contact specular microscope (Tomey EM-1000, Tokyo, Japan) by one ophthalmologist, blind to which surgical technique was used. A total of 3-10 photographs were taken from the central region to perform cell analysis using the fixed frame method. The best three images marked with a $0.04 \mathrm{~mm}^{2}$ grid including approximately 90 cells were used for image analysis. Endothelial cell density (ECD) and additional morphologic parameters such as mean endothelial cell area and coefficient of variation in cell size (an objective measure of polymegathism) were determined with the image-analysis software (Tomey EM-1100, version 1.5.1). ECL was defined using the following equation

$$
\begin{aligned}
\mathrm{ECL}= & (\mathrm{ECD} \text { preoperative } \\
& -\mathrm{ECD} 1 \text { year }) / \mathrm{ECD} \text { preoperative } \times 100
\end{aligned}
$$

Considering thickness, the normalized magnification conversion table - provided by the manufacturer - was used to ensure an accurate cell count.

\section{Pachymetry}

CCT was measured with an ultrasound pachymeter (AL-2000, Tomey, Erlangen, Germany). Three measurements were taken at the centre of the cornea and the mean values were recorded.

\section{Statistical analysis}

The statistical analysis was performed by an independent professional statistician using SPSSWIN12 software (SPSS Inc., Chicago, IL, USA). The data were indicated descriptively (mean values \pm standard deviation (SD) and range). The normality of the investigated data was checked with KolmogorovSmirnov test. In case of surgical parameters and visual acuity data, the normality was rejected $(P<0.05)$ and nonparametric test was used (Mann-Whitney). The distribution of endothelial functions data (ECD, mean cell size, coefficient of variation in cell size, ECL, and CCT) was normal $(P>0.05)$; therefore, the parametric two-way repeated measure ANOVA was used. The 'group' (fluid-based $v s$ ultrasound) was between-subject factor and the 'time' was within-subject factor. The effect of time was calculated with 'simple' and 'repeated' contrast, having preoperative or previous measurement as reference category. A $P$-value of 0.05 was considered as the level of significance.

\section{Results}

The mean age was $72.7 \pm 5.9$ years (range: $58-80$ years) in the fluid-based group and $73.4 \pm 7.4$ years (range: $59-86$ years) in the ultrasound group $(P=0.77)$.

At 1 year after surgery, the mean BCDVA was logMAR $0.03 \pm 0.09$ (range: -0.2 to 0.1 ) in Group 1 and $0.00 \pm 0.08$ (range: -0.18 to 0.12 ) in Group 2.

The nucleus hardness was similar in both groups (mean: $3.4 \pm 0.8$ in the fluid-based group and $3.5 \pm 0.9$ in the ultrasound group) $(P=0.81)$. Surgical parameters are summarized in Table 1.

Alterations of all evaluated parameters were similar in both groups during the postoperative period (the interaction between 'group' and 'time' was not significant).

Significant changes were detected during the study in the CCT $(P<0.001, \mathrm{~F}=20.6, \mathrm{df}=4$ and 42$)$, in the ECD $(P<0.001, \mathrm{~F}=10.7, \mathrm{df}=4$ and 41$)$, and in the mean cell size $(P<0.001, \mathrm{~F}=9.2, \mathrm{df}=4$ and 41$)$, but no significant alteration was found in the coefficient of variation in cell size $(P=0.08, \mathrm{~F}=2.3, \mathrm{df}=4$ and 41$)$. The 'group' had no significant effect within the investigated parameters. (All results are shown in detail in Table 2.)

Investigating each parameter separately, an acute increase of CCT was found in both groups, which was reversible after 1 month ('simple contrast', $P<0.001$, $P=0.02, P=0.43, P=0.06)$. The changes of the CCT were similar in both groups $(P=0.35)$.

ECD decreased immediately after surgery in both groups. Additional reduction of ECD was not found after the first postoperative visit; however, a slight increase was observed at the 1-year visit ('repeated contrast', $P<0.001, P=0.4, P=0.28, P=0.01$ ). The amount of ECD decrease was similar in both groups $(P=0.99)$.

Mean cell size increased significantly at once after surgery in both groups; 10 days to 3 months it stabilized; and after that, a slight decrease was detected ('repeated contrast' $P<0.001, P=0.66, P=0.53, P=0.01$ ). The changes of mean cell size were similar in both groups $(P=0.85)$.

The coefficient of variation in cell size remained stable after surgery $(P=0.08)$. Significant difference was not found between groups $(P=0.99)$.

ECL was $6.5 \pm 8.4 \%$ (range: 0-20.8) in Group 1 and $6.5 \pm 11.7 \%$ (range: $0-24.2$ ) in Group 2, 1 year after surgery $(P=0.69)$. 
Table 1 Surgical parameters

\begin{tabular}{|c|c|c|c|}
\hline & $\begin{array}{c}\text { Group } 1 \text { (fluid-based) } \\
(\text { mean } \pm S D \text { (range) })\end{array}$ & $\begin{array}{l}\text { Group } 2 \text { (ultrasound) } \\
(\text { mean } \pm S D \text { (range) })\end{array}$ & $P$ \\
\hline Nucleus hardness (LOCS III) & $3.4 \pm 0.8(2.2-5.2)$ & $3.5 \pm 0.9(2.2-6)$ & 0.81 \\
\hline \multicolumn{4}{|l|}{ Clear corneal incision (eyes) } \\
\hline Temporal & 22 & 20 & \\
\hline $12 \mathrm{O}^{\prime}$ clock & 3 & 5 & \\
\hline Flow rate $(\mathrm{ml} / \mathrm{min})$ & 35 & 35 & \\
\hline \multirow[t]{2}{*}{ Vacuum (Hgmm) } & Sculpting: 70 & Sculpting: 70 & \\
\hline & Quadrant removal: 500 & Quadrant removal: 500 & \\
\hline \multirow[t]{2}{*}{ Fluid-based magnitude/Phaco power (\%) } & Sculpting: 80 & Sculpting: 80 & \\
\hline & Quadrant removal: $40-100$ & Quadrant removal: $40-70$ & \\
\hline Fluid-based/phaco time (s) & $2.7 \pm 1.9(0.6-9)$ & $22.9 \pm 13.8(4.4-53.9)$ & $<0.001$ \\
\hline Average fluid-based magnitude/Average phaco power (\%) & $56.8 \pm 14.8(3-81)$ & $10 \pm 4.9(2-19)$ & $<0.001$ \\
\hline Effective fluid-based/phaco time (s) & $1.6 \pm 1.5(0.1-7.3)$ & $2.5 \pm 2.2(0.1-8.9)$ & 0.11 \\
\hline Number of pulses & $3716 \pm 2410(1050-10770)$ & & \\
\hline Aspiration time (min) & $\overline{6} \pm 1.5(3.4-9)$ & $6.7 \pm 1.6(4.3-11)$ & 0.14 \\
\hline Surgery time (min) & $15.9 \pm 3.3(10.7-22.6)$ & $16.2 \pm 3.2(10-22.2)$ & 0.73 \\
\hline
\end{tabular}

Number of pulses $=$ sum of $4 \mu \mathrm{l}$ water pulses during the surgery.

$P<0.05=$ statistically significant.

Table 2 Endothelial function parameters

\begin{tabular}{|c|c|c|c|}
\hline & $\begin{array}{l}\text { Group } 1 \text { (fluid-based) } \\
(\text { mean } \pm S D \text { (range) })\end{array}$ & $\begin{array}{l}\text { Group } 2 \text { (ultrasound) } \\
(\text { mean } \pm S D \text { (range) })\end{array}$ & $P$ \\
\hline Central corneal thickness $(\mu m)$ & & & 0.35 \\
\hline Preoperative & $538 \pm 32(480-608)$ & $551 \pm 35(473-608)$ & \\
\hline Day 10 & $575 \pm 40(480-652)$ & $589 \pm 42(511-674)$ & \\
\hline Month 1 & $549 \pm 35(484-628)$ & $560 \pm 30(511-643)$ & \\
\hline Month 3 & $541 \pm 34(473-614)$ & $550 \pm 40(467-685)$ & \\
\hline Year 1 & $536 \pm 29(468-593)$ & $547 \pm 43(467-685)$ & \\
\hline Endothelial cell density (cells/ $/ \mathrm{mm}^{2}$ ) & & & 0.99 \\
\hline Preoperative & $2148 \pm 265(1650-2750)$ & $2134 \pm 308(1666-2767)$ & \\
\hline Day 10 & $1945 \pm 264(1383-2533)$ & $1888 \pm 300(1450-2483)$ & \\
\hline Month 1 & $1906 \pm 289(1367-2650)$ & $1853 \pm 255(1367-2300)$ & \\
\hline Month 3 & $1946 \pm 290(1350-2800)$ & $1875 \pm 273(1367-2333)$ & \\
\hline Year 1 & $1999 \pm 231(1450-2550)$ & $1996 \pm 214(1567-2317)$ & \\
\hline Mean cell size $\left(\mu m^{2}\right)$ & & & 0.85 \\
\hline Preoperative & $471 \pm 59(364-606)$ & $480 \pm 84(360-597)$ & \\
\hline Day 10 & $523 \pm 73(396-721)$ & $545 \pm 90(403-770)$ & \\
\hline Month 1 & $537 \pm 89(375-784)$ & $551 \pm 88(434-800)$ & \\
\hline Month 3 & $531 \pm 80(376-737)$ & $544 \pm 91(432-786)$ & \\
\hline Year 1 & $509 \pm 59(395-680)$ & $505 \pm 59(433-641)$ & \\
\hline Coefficient of variation in cell size $\left(\mathrm{SD} / \mu \mathrm{m}^{2}\right)$ & & & 0.99 \\
\hline Preoperative & $0.47 \pm 0.07(0.35-0.63)$ & $0.49 \pm 0.1(0.37-0.91)$ & \\
\hline Day 10 & $0.51 \pm 0.1(0.37-0.8)$ & $0.52 \pm 0.1(0.35-0.8)$ & \\
\hline Month 1 & $0.48 \pm 0.06(0.35-0.64)$ & $0.48 \pm 0.08(0.38-0.7)$ & \\
\hline Month 3 & $0.48 \pm 0.08(0.36-0.68)$ & $0.49 \pm 0.07(0.35-0.63)$ & \\
\hline Year 1 & $0.48 \pm 0.07(0.36-0.62)$ & $0.48 \pm 0.07(0.35-0.63)$ & \\
\hline
\end{tabular}

\section{Discussion}

Corneal endothelial cells are crucial to corneal transparency and integrity. Because these cells are non-dividing, the possibility of regeneration is limited after trauma. It is known that less surgical trauma causes lower endothelial damage. ${ }^{2}$ ECL can occur during phacoemulsification from many causes such as hard and 
large nucleus, direct endothelial contact with nuclear fragments or intraocular lens (IOL) or air bubbles or surgical instruments, greater irrigation volume, type and implantation technique of IOL, ultrasound energy, short axial length, release of free radicals, small pupil, advanced age, and toxic injury from intraoperative medications. ${ }^{4-7,25-27}$ Besides the above-mentioned parameters, the skill of the surgeon is still crucial.

Seeking an alternative to ultrasound phacoemulsification, investigators have tested several types of technologies to reduce ECL and heating effect of the procedure. These systems include lasers, sonic energy, and the newly developed fluid-based method. All nuclei could be divided under the direct force of water-jet. ${ }^{28}$ The only reported limitation of fluid-based system is that it is not as effective as conventional ultrasound technique. ${ }^{21,29}$ Our experiences are similar. Specifically, subjects with hard nuclei required longer surgery time and more applied energy with the fluid-based technique, and ultrasound proved to be more effective in these cases. In our opinion, ultrasound technique remains advisable in patients with hard cataract. However, we found that the effective fluidbased time was slightly less in the water-jet group than the effective phaco time in the ultrasound group (the difference was not statistically significant). For this reason, great caution should be taken with direct comparison of these two totally different methods.

Studies of the corneal endothelium provide us with essential information in the cell function after the application of a new surgical technique. Investigators can gain useful information about the endothelial cell function from the increase of corneal thickness and the alterations in endothelial cell count, cell size (polymegathism), and the proportion of hexagonal cells (polymorphism). To the best of our knowledge, this is the first in vivo study evaluating the effect of fluid-based phacoemulsification on corneal endothelium.

In this clinical study, we used the recently developed Infiniti $^{\mathrm{TM}}$ lens removal system, which is capable of fluid-based as well as conventional ultrasound techniques, and the two methods were compared. The phacoemulsification was performed by the same surgeon using standardized technique to reduce bias. Aspiration time and surgery time were similar in both groups; therefore, our results were not affected by these factors. Intra- and postoperative complications and 'corneal burn' did not occur in our patients.

In this study, we found an acute reversible increase of CCT after surgery, in accordance with other authors' data. ${ }^{12}$ The amount of increase was similar in both groups. ECD decreased, whereas mean cell size increased significantly after surgery in both groups. Additional worsening did not occur after 1 month. These results are in good correlation with other authors' data. ${ }^{3,5} \mathrm{We}$ found similar ECL in the fluid-based and the ultrasound groups. The coefficient of variation in cell size was also similar in the two groups after surgery. In this investigation, the original Aqualase tip was used. Larger studies are needed to validate our findings on corneal endothelial changes after phacoemulsification using fluid-based method. Further trials are also needed with improved tip, which has increased holding force and cutting efficiency and may decrease surgery time.

Our results are only valid for the divide and conquer technique, but not necessarily to other techniques such as phaco chop and prechop that can reduce ECL. ${ }^{19,25-27}$ It is known that endothelial cell survival depends on the type of OVD used. ${ }^{11,12,15,18}$ It is unclear whether ECL decreases using phaco chop technique during fluid-based phacoemulsification. Further prospective randomized clinical trials are needed to investigate ECL in different nuclear fragmentation techniques and using different OVD's during water-jet procedure.

In conclusion, we were the first to demonstrate that the endothelial functions are similar using the water-jet system compared to the traditional ultrasound technique. The fluid-based method proved to be as safe as conventional ultrasound in cataract surgery.

\section{References}

1 Kohnen T. Corneal endothelium: an important structure for cataract and refractive procedures. J Cataract Refract Surg 1997; 23: 967-968.

2 Ravalico G, Tognetto D, Palomba MA, Lovisato A, Baccara F. Corneal endothelial function after extracapsular cataract extraction and phacoemulsification. J Cataract Refract Surg 1997; 23: 1000-1005.

3 Wirbelauer C, Wollensak G, Pham DT. Influence of cataract surgery on corneal endothelial cell density estimation. Cornea 2005; 24: 135-140.

4 Beltrame G, Salvetat ML, Driussi G, Chizzolini M. Effect of incision size and site on corneal endothelial changes in cataract surgery. J Cataract Refract Surg 2002; 28: 118-125.

5 Bourne RR, Minassian DC, Dart JK, Rosen P, Kaushal S, Wingate N. Effect of cataract surgery on the corneal endothelium: modern phacoemulsification compared with extracapsular cataract surgery. Ophthalmology 2004; 111: 679-685.

6 O'Brien PD, Fitzpatrick P, Kilmartin DJ, Beatty S. Risk factors for endothelial cell loss after phacoemulsification surgery by a junior resident. J Cataract Refract Surg 2004; 30: 839-843.

7 Zetterström C, Laurell CG. Comparison of endothelial cell loss and phacoemulsification energy during endocapsular phacoemulsification surgery. J Cataract Refract Surg 1995; 21: 55-58.

8 Diaz-Valle D, Benitez del Castillo Sanchez JM, Castillo A, Sayagues O, Moriche M. Endothelial damage with cataract surgery techniques. J Cataract Refract Surg 1998; 24: 951-955. 
9 Dick HB, Kohnen T, Jacobi FK, Jacobi KW. Long-term endothelial cell loss following phacoemulsification through a temporal clear corneal incision. J Cataract Refract Surg 1996; 22: 63-71.

10 Elvira JC, Hueso JR, Martinez-Toldos J, Mengual E, Artola A. Induced endothelial cell loss in phacoemulsification using topical anesthesia plus intracameral lidocaine. J Cataract Refract Surg 1999; 25: 640-642.

11 Holzer MP, Tetz MR, Auffarth GU, Welt R, Volcker HE. Effect of Healon 5 and 4 other viscoelastic substances on intraocular pressure and endothelium after cataract surgery. J Cataract Refract Surg 2001; 27: 213-218.

12 Kiss B, Findl O, Menapace R, Petternel V, Wirtitsch M, Lorang $\mathrm{T}$ et al. Corneal endothelial cell protection with a dispersive viscoelastic material and an irrigating solution during phacoemulsification: low-cost versus expensive combination. J Cataract Refract Surg 2003; 29: 733-740.

13 Kosrirukvongs P, Slade SG, Berkeley RG. Corneal endothelial changes after divide and conquer versus chip and flip phacoemulsification. J Cataract Refract Surg 1997; 23: 1006-1012.

14 Kramann C, Pitz S, Schwenn O, Haber M, Hommel G, Pfeiffer N. Effects of intraocular cefotaxime on the human corneal endothelium. J Cataract Refract Surg 2001; 27: 250-255.

15 Maár N, Graebe A, Schild G, Stur M, Amon M. Influence of viscoelastic substances used in cataract surgery on corneal metabolism and endothelial morphology: comparison of Healon and Viscoat. J Cataract Refract Surg 2001; 27: 1756-1761.

16 Matsuda M, Miyake K, Inaba M. Long-term corneal endothelial changes after intraocular lens implantation. $A m$ J Ophthalmol 1998; 105: 248-252.

17 Milla E, Verges C, Cipres M. Corneal endothelium evaluation after phacoemulsification with continuous anterior chamber infusion. Cornea 2005; 24: 278-282.

18 Miyata K, Nagamoto T, Maruoka S Tanabe T, Nakahara M, Amano S. Efficacy and safety of the soft-shell technique in cases with a hard lens nucleus. J Cataract Refract Surg 2002; 28: 1546-1550.
19 Pirazzoli G, D’Eliseo D, Ziosi M, Acciarri R. Effects of phacoemulsification time on the corneal endothelium using phacofracture and phaco chop techniques. J Cataract Refract Surg 1996; 22: 967-969.

20 Walkow T, Anders N, Klebe S. Endothelial cell loss after phacoemulsification: relation to preoperative and intraoperative parameters. J Cataract Refract Surg 2000; 26: 727-732.

21 Mackool RJ, Brint SF. Aqualase: a new technology for cataract extraction. Curr Opin Ophthalmol 2004; 15: 40-43.

22 Sandoval HP, Al Sarraf O, Vroman DT, Solomon KD. Corneal endothelial cell damage after lens extraction using the fluid-based system compared to ultrasound phacoemulsification in human cadaver eyes. Cornea 2004; 23: 720-722.

23 Chylack LT, Wolfe JK, Singer DM, Leske MC, Bullimore MA, Bailey IL et al. The lens opacities classification system III. Arch Ophthalmol 1993; 111: 831-836.

24 Smith JMA, El-Brawany M, Nassiri D, Tabandeh H, Thompson GM. The relationship between nuclear colour and opalescence on the LOCSIII scale and physical characteristics of cataract nuclei. Eye 2002; 16: 543-551.

25 Can I, Takmaz T, Cakici F, Ozgul M. Comparison of Nagahara phaco-chop and stop-and-chop phacoemulsification nucleotomy techniques. J Cataract Refract Surg 2004; 30: 663-668.

26 Hayashi K, Hayashi H, Nakao F, Hayashi F. Risk factors for corneal endothelial injury during phacoemulsification. J Cataract Refract Surg 1996; 22: 1079-1084.

27 Vargas LG, Holzer MP, Solomon KD, Sandoval HP, Auffarth GU, Apple DJ. Endothelial cell integrity after phacoemulsification with 2 different handpieces. J Cataract Refract Surg 2004; 30: 478-482.

28 Wilhelm F, Holtkamp A, Duncker GIW, Darman J, Knorrn M. Phacoemulsification of human lens nucleus with a water jet. Ophthalmologe 2002; 99: 286-288.

29 Hughes EH, Mellington FE, Whitefield LA. Aqualase for cataract extraction. Eye (advance online publication 25 November 2005; doi 10.1038/sj.eye.6702162). 